\title{
Niemann-Pick Type C Disease: At the Nexus of Neurodegenerative and Neurodevelopmental Disorders
}

\begin{abstract}
Rare genetic diseases can provide valuable insights into more common disorders by linking specific genes and pathways to shared disease phenotypes. The rare Niemann-Pick Type C disease (NPC) is a neurological disorder that has often been compared to Alzheimer's Disease (AD) because both diseases are characterized by cognitive impairment in the presence of tau pathology and altered Amyloid Precursor Protein (APP) processing and $A B$ metabolism. Here we review the molecular pathology of NPC and critically examine the similarities between NPC, AD and other neurological disorders. Besides the phenotypic overlap between AD and NPC, there is substantia evidence that cholesterol metabolism is altered in both diseases. Specifically, the epsilon 4 allele of the brain cholesterol transport protein Apolipoprotein E (ApoE4) is the strongest risk factor for late onset AD (LOAD) whereas NPC disease is caused by point mutations in the cholesterol transport proteins NPC1 and NPC2. In contrast to $A D, N P C$ encompasses a broad neurovisceral disease phenotype having a diversity of penetrance, age of onset, and both central and peripheral manifestations. In addition to features that are in common with AD, NPC frequently exhibits close phenotypic overlap with neurodevelopmental disorders such as schizophrenia. Understanding the mechanistic links shared by NPC, AD, and neurodevelopmental disorders should enable a more holistic approach to therapeutic strategies to diseases which superficially appear very different.
\end{abstract}

\section{Introduction}

Neurodevelopmental and neurodegenerative diseases are generally thought to differ fundamentally in cause, course of disease and disease phenotype. Neurodevelopmental diseases arise from perturbed development of the nervous system while neurodegenerative diseases emerge from chronic degenerative changes in the brain resulting from stress, injury, altered metabolism or other maladaptive processes. As will be discussed in detail below, the Niemann-Pick disease type C (NPC) clinical phenotype includes psychosis and dementia [1,2], features of the common neurodevelopmental disease schizophrenia and the most common neurodegenerative disease Alzheimer's Disease (AD) [3,4], respectively. NPC results from mutations in either of two cholesterol transport proteins, NPC1, or NPC2, highlighting the fundamental role played by cholesterol homeostasis in brain function and disease [5,6]. These neurodevelopmental and neurodegenerative processes may engage components of lipid metabolism in reciprocal ways frustrating the therapeutic targeting of many pathway components however, comparing the NPC phenotype to $\mathrm{AD}$ brings to light symptoms not normally associated with $\mathrm{AD}$, such as psychosis [7-9]. This suggests that certain $\mathrm{AD}$ features or population subtypes may have characteristics of neurodevelopmental diseases such as alterations in developmental signaling pathways [1014].
Journal of

Parkinson's disease $\&$ Alzheimer's disease

\author{
Martone $\mathbf{R}^{\mathbf{1}}$, Gonzales $\mathbf{C}^{\mathbf{2}}$ and Ramaswamy $\mathbf{G}^{\mathbf{2}^{*}}$ \\ ${ }^{1}$ Translational Sciences and \\ 'Alzheimer's Disease \& Dementia Research Unit, Biogen Inc, USA \\ *Address for Correspondence
}

Ramaswamy G, Alzheimer's Disease \& Dementia Research Unit, Biogen Inc, 115 Broadway Cambridge MA 02142, USA; E-mail: gayathri.ramaswamy1@biogen.com

Submission: 25-October-2019

Accepted: 10-December-2019

Published: 13- December -2019

Copyright: $\odot 2019$ Martone R, et al. This is an open access article distributed under the Creative Commons Attribution License, which permits unrestricted use, distribution, and reproduction in any medium, provided the original work is properly cited.

\section{Niemann-Pick Type C Disease Clinical Phenotype (Table 1)}

Niemann-Pick disease is a rare autosomal recessive disease with an incidence of 1:120,000 live births. Mutations in NPC1 account for $95 \%$ of disease and number $>140$ clinical variants. NPC2 mutations are less common with $>40$ known variants. Infantile, juvenile and adult onset forms are recognized. Early infantile forms result in death by 6 years of age, late infantile by 12 years of age and juvenile forms typically cause death in the third decade of life. Age at diagnosis from a cohort of 200 NPC patients showed that $45 \%$ were aged between 2 and 10 years [15]. Cerebral MRI reveals distinct patterns of brain atrophy associated with each form [16]. Infantile and juvenile forms of NPC present with anatomical abnormalities in the liver, spleen (hepatosplenomegaly) and cerebellar Purkinje cell atrophy.

Behaviorally, there is motor developmental delay, language delay, mental regression, vertical supranuclear gaze palsy and cataplexy [17]. Mutations in NPC1 or NPC2 cause cholesterol transport dysfunction that results in sequestration and accumulation in the late endosome and lysosome. Adult forms of the disease have also been identified in subjects in their 60 's suggesting variable penetrance $[18,19]$. In adult onset NPC, patients have cortical, cerebellar and midbrain, and liver abnormalities, but hepatosplenomegaly is less pronounced than in the younger forms. Adult onset NPC has increased neurofibrillary tangles, neurodegeneration and CSF $A \beta$, In some cases, diffuse $A \beta$ plaques were found in the brain of the adult NPC patients that carried two copies of the ApoE4 allele [20].

NPC is characterized by extensive visceral and neurological signs including dementia in the presence of extensive neurodegeneration with tau pathology, increased $A \beta$ levels and increased secretase activity reminiscent of $\mathrm{AD}$; the disease has been referred to as a "childhood Alzheimer's disease" [21]. However, distinct from AD, cerebellar Purkinje cells are heavily impacted in NPC leading to ataxia [22], a pattern that is recapitulated in animal models [23]. Heterozygous carriers of NPC mutations may exhibit visceral manifestations of dysregulated cholesterol metabolism, such as obesity [24]. Parkinsonism has been reported in NPC1 heterozygotes further expanding the spectrum of disease phenotypes associated with 
Citation: Martone R, Gonzales C, Ramaswamy G. Niemann-Pick Type C Disease: At the Nexus of Neurodegenerative and Neurodevelopmental Disorders. J Parkinsons Dis Alzheimer Dis. 2019;6(1): 10.

Table 1: Phenotypic similarities between NPC Disease, AD \& Schizophrenia.

\begin{tabular}{|c|c|c|c|c|}
\hline $\begin{array}{c}\text { Neurological Disorder age of } \\
\text { onset }\end{array}$ & Anatomical Pathology & Neuropathology & Behavioural Pathology & Lipid Metabolism \\
\hline NP-C & \multirow[b]{2}{*}{$\begin{array}{l}\text { Liver, spleen (heptosplenomegaly), } \\
\text { cerebellar Purkinje cells }\end{array}$} & \multirow[b]{2}{*}{ Cerebral and cerebellar atrophy } & \multirow{2}{*}{$\begin{array}{l}\text { Motor developmental } \\
\text { delay, language delay, } \\
\text { mental regression, } \\
\text { cataplexy }\end{array}$} & \multirow{3}{*}{$\begin{array}{c}\text { (All forms) } \\
\text { Mutations in } \\
\text { NPC1 and NPC2 } \\
\text { cholesterol } \\
\text { transport proteins } \\
\text { resulting in } \\
\text { cholesterol } \\
\text { sequestration and } \\
\text { accumulation in the } \\
\text { late endosome and } \\
\text { lysosome }\end{array}$} \\
\hline Infantile and Juvenile & & & & \\
\hline Adult & $\begin{array}{l}\text { Cortex, cerebellum and midbrain, in liver } \\
\text { hepatosplenomegaly is less pronounced } \\
\text { than the younger forms }\end{array}$ & $\begin{array}{l}\text { Neurofibrillary tangles, } \\
\text { neurodegeneration, CSF } A \beta \text {, } \\
\text { diffuse } A \beta \text { plaques found in } \\
\text { some } A \text { poE4/E4 carriers }\end{array}$ & $\begin{array}{c}\text { Dementia, psychiatric } \\
\text { cerebellar ataxia, vertical } \\
\text { supranuclear gaze palsy } \\
\text { (VSGP), movement } \\
\text { disorders, dysarthria, } \\
\text { dysphagia, and cataplexy }\end{array}$ & \\
\hline AD & Hippocampus, entorhinal cortex, neocortex & $\begin{array}{l}\text { Neurofibrillary tangles, } A \beta \\
\text { plaques, neurodegeneration }\end{array}$ & \multirow{2}{*}{$\begin{array}{l}\text { Cognitive impairment, } \\
\text { dementia, psychosis, } \\
\text { agitation, apathy, } \\
\text { depression, and sleep } \\
\text { disturbances }\end{array}$} & \multirow{2}{*}{$\begin{array}{c}\text { ApoE4 carriers } \\
\text { have a high risk } \\
\text { of } A D \text { and } A D+ \\
\text { psychosis. } 40-60 \% \\
\text { of } A D \text { patients } \\
\text { carry at least one } \\
\text { ApoE4 allele }\end{array}$} \\
\hline AD + Psychosis Adult & Hypofrontality & Lewy Bodies & & \\
\hline Schizophrenia Adult & $\begin{array}{l}\text { Prefrontal cortex, hippocampus, } \\
\text { pyramidal cells, neuro-oligodendrocytes, } \\
\text { interneurons, cerebellum }\end{array}$ & $\begin{array}{l}\text { Decreased white matter } \\
\text { and brain volume, enlarged } \\
\text { ventricles, lower spine density, } \\
\text { fewer oligodendrocytes, } \\
\text { reduced GABA transmission }\end{array}$ & $\begin{array}{c}\text { Psychosis, delusions, } \\
\text { hallucinations, thought } \\
\text { disorder, cognitive deficits } \\
\text { and apathy }\end{array}$ & $\begin{array}{c}\text { Elevated free fatty } \\
\text { acids; metabolic } \\
\text { syndrome, obesity, } \\
\text { type II diabetes } \\
\text { and cardiovascular } \\
\text { disease prevalent } \\
\text { in drug -naïve } \\
\text { patients }\end{array}$ \\
\hline
\end{tabular}

Table 2: NPC Modulation of Pathology in AD and AD Mouse Models.

\begin{tabular}{|c|c|}
\hline Reference & Human Studies \\
\hline $\begin{array}{l}\text { Kagedal et al., } \\
2010[109]\end{array}$ & $\begin{array}{l}\text { NPC1 protein and mRNA expression is upregulated in neurons of the hippocampus and frontal cortex of AD patients. No difference was found in } \\
\text { cerebellum }\end{array}$ \\
\hline $\begin{array}{l}\text { Fu et al., } 2012 \\
\quad[154]\end{array}$ & $\begin{array}{l}\text { Significant associations were found in NP-C patients between ApoE polymorphism and phenotypic severity. Patients with an ApoE4 allele have } \\
\text { greater disease severity than ApoE3 and those with ApoE2 are less severely effected than those with ApoE3 }\end{array}$ \\
\hline Reference & Mouse Models \\
\hline $\begin{array}{l}\text { Kagedal et al., } \\
2010[109]\end{array}$ & NPC1 mRNA levels were increased in hippocampus of APP/PS1 tg mice compared to wild type, no change in NPC1 was detected in cerebellum \\
\hline $\begin{array}{l}\text { Yang et al., } 2017 \\
{[152]}\end{array}$ & Amelioration of intra - Iysosomal accumulations of $A \beta$-immunoreactive material and lipids in TgCRNDB mouse by cyclodextrin. \\
\hline $\begin{array}{l}\text { Maulik et al., } \\
2012[153]\end{array}$ & Mutant human APP exacerbates pathology in a mouse model of NPC and is reversed by cyclodextrin \\
\hline $\begin{array}{l}\text { Borbon et al., } \\
2011[116]\end{array}$ & NPC1 hetrozygous knockout mice crossed to PSAPP mice accumulate A $\beta$ plaques more rapidly and plaques are larger than PSAPP alone \\
\hline $\begin{array}{l}\text { Nunes et al., } \\
2011[112]\end{array}$ & Loss of APP in NPC -/- mice (APP -/- NPC-/-) worsens NPC pathology; specifically motor coordination, cholesterol regulation, tau homeostatis \\
\hline $\begin{array}{l}\text { Pacheco et al., } \\
2009 \text { [111] }\end{array}$ & $\begin{array}{c}\text { NPC1 -/- mice with tau depletion (crossed with MAPT-/-) had exacerbated NPC1 pathology by exhibiting an enhanced systematic phenotype } \\
\text { and younger mortality rate }\end{array}$ \\
\hline
\end{tabular}

NPC mutations [25]. Genetic screening studies reveal that a late onset phenotype might be present with a much higher incidence, between 1:19,000-1:36,000 [26], and may be overrepresented and under diagnosed among adults with neurological and psychiatric symptoms [27]. These findings suggest that there is a wealth of opportunity to explore modulators of disease severity.

\section{Molecular Pathology of NPC (Figure 1)}

Both NPC1 and NPC2 work in concert as cholesterol binding proteins that regulate transport of LDL-derived cholesterol to the endosome and from the late endosome to various intracellular targets including the endoplasmic reticulum, lysosome, Golgi and mitochondria $[28,29]$. Expression of both proteins is regulated by cholesterol levels via SREBP pathways.

$\mathrm{NPC} 1$ is an intrinsic membrane protein having an N-Terminal Domain (NTD), three luminal domains and 13 transmembrane helices several of which comprise a sterol sensing domain [30]. NPC1 mutations alter not only cholesterol binding and transport functions but also expression levels, processing and localization in a mutationrelated manner [31,32]. NPC1 protein has significant homology to the Patched1 (Ptc1) morphogen receptor that is part of the Hedgehog (Shh) pathway [33] and, along with Ptc1, significant homology to the resistance-nodulation-division (RND) family of permeases suggesting a role in fatty acid and multidrug transport [34].

The NPC2 protein is a soluble protein that was originally identified 


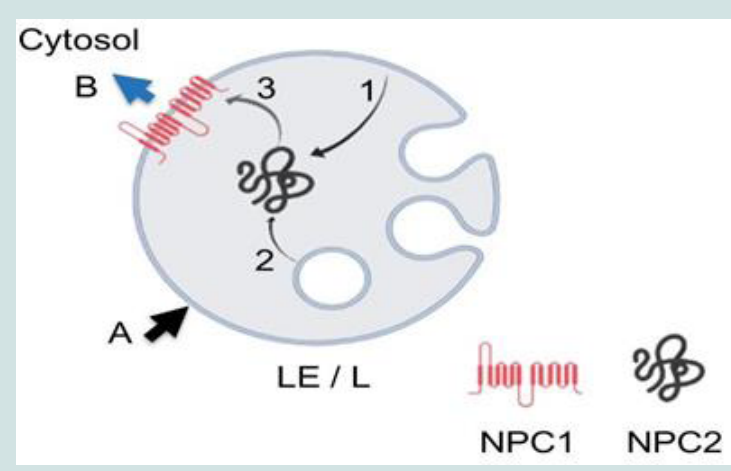

Figure 1: NPC1 and NPC2 proteins in cholesterol transport.

Cholesterol, primarily from LDLR transport is taken up (A) into late endosomelysosome (LE/L). Membrane associated (1) and vesicular cholesterol (2) is transported by NPC2 to NPC1 (3) and via NPC1 to the cytosol (B).

as human epididymal secretory protein 1 (HE1). Mutations in NPC2 are implicated in 5\% of NPC disease and often features frontal lobe atrophy [35,36]. A diversity of NPC2 glycoforms are normally expressed that transfer LDL-derived cholesterol and cholesterolrelated molecules from LDLR to NPC1 and between NPC1 and lipid bilayers $[37,38]$.

Additionally, NPC2 transports cholesterol from the endosome to mitochondria where it plays an important role in regulating mitophagy $[39,40]$. The golgi-associated retrograde protein (GARP) complex is required for the targeting of NPC2 mediated intracellular cholesterol transport [41]. The expression and secretion of NPC2 protein are regulated by cathepsin B and L [42], and it interacts with neural precursor cell expressed developmentally downregulated gene 4-like (Nedd4L), a regulator of epithelial sodium channels $(\mathrm{ENaC})$ and of mammalian target of rapamycin (mTOR) [43,44].

Mutations in NPC1 and NPC2 proteins impair cholesterol transport functions leading to endosomal accumulation of cholesterol [45], impairing lysosomal activity and autophagy, and impacting multiple signaling pathways leading to neuronal cell death [40]. A basic relationship between genotype and phenotype for NPC1 and NPC2 mutations have been reported [31,35].

\section{NPC Protein Interactions and Cellular Pathways (Figure 2)}

The expression and protein stability of NPC proteins are influenced by numerous interacting proteins suggesting possible strategies for therapeutic intervention through the manipulation of NPC protein levels.

\section{NPC1}

Levels of NPC1 are regulated by TMEM97/б2 receptor [46] Knockdown of TMEM97/\%2 increases NPC1 protein levels in cell culture but anti-sense oligomers (ASOs) to TMEM97/ס2 failed to influence NPC1 levels in vivo in rat liver. It is unclear whether brain NPC1 levels would have responded if brain penetrant ASOs had been employed. It has been suggested that TMEM97/\%2 may act as a chaperone protein for NPC1 limiting its generation and export from the endoplasmic reticulum (ER) TMEM97/ 22 is itself a robust target for neuropsychiatric compounds including haloperidol, ketamine, methamphetamine and phencyclidine (all agonists).

TMEM97/б2 is involved in one of several complexes with the low-density lipoprotein receptor (LDLR) upstream of NPC1 that may be differentially regulated among different tissues. TMEM97/ 22 forms a complex with progesterone receptor membrane component 1 (PGRMC1) and LDLR to promote internalization of LDL [47]. LDLR also forms clathrin-dependent internalization complexes with proprotein convertase subtilisin/kexin-9 (PCSK-9) and the adaptor protein autosomal hypercholesterolemia (ARH)/ receptor associated protein (LDLRAP). LDLRAP protein levels are high in liver but low in brain and may provide an alternative to TMEM97/ 22 for LDLR internalization in liver.

Levels of LDLR are promoted in NPC1 defective cells by the metastatic suppressor $\mathrm{N}$-myc downstream regulated gene-1 (NDRG1) which is required for caspase activation by tumor protein p53 (TP53) [48]. NDRG1 effects balance degradation of the receptor by the inducible degrader of the LDLR (IDOL) [49]. TP53 protein is reduced in Niemann Pick's disease as a result of abnormal p38MAPK activation and subsequent $\mathrm{Mdm} 2$ activation resulting in TP53 degradation [50]. In contrast in $\mathrm{AD}$, there is evidence that TP53 activity is increased and that there are direct interactions with tau and A $\beta$ while others have reported conformational alterations of TP53 associated with $\mathrm{AD}$ [51-53].

Transcriptional profiling of NPC1 knockout mice links NPC1 to levels of tau, apolipoprotein C1 (ApoC1), sortilin 1, nexins 12, 13, 17 , and ATP-binding cassette sub-family A (ABCA) members 2, 5 , and $8 \mathrm{~B}$ which are all related to active targets for intervention in $\mathrm{AD}$. ABCA2, for example, is reported to regulate amyloid precursor protein (APP) expression via sphingolipid metabolism [54,55]. APP protein increases in cerebellum and hippocampus of NPC1 knockout mice [56]. Reduction of NPC1 levels by proteasomal degradation [57], is a consequence of Akt activation.

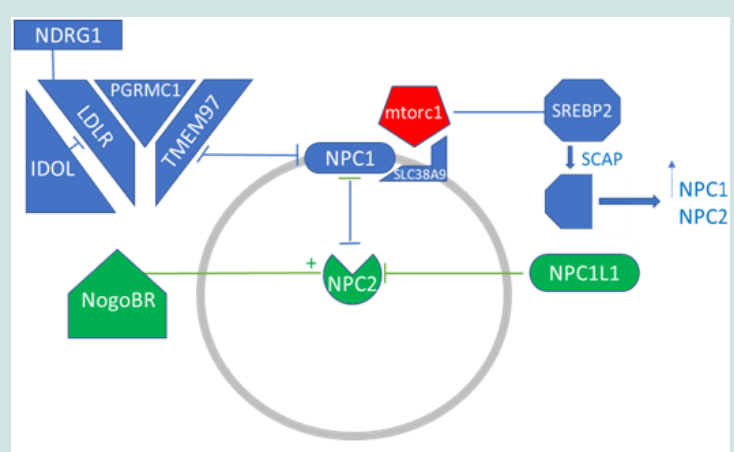

Figure 2: Regulators of NPC1 and NPC2 protein levels.

NPC1 levels appear to be reciprocally regulated by TMEM97/б2 receptor. TMEM97 forms a complex with PGRMC1 and LDLR. LDLR levels are enhanced by NDRG1, and down regulated by IDOL (left). NPC1 directly interacts with SLC38A9 to mediate cholesterol activation of $\mathrm{mTORC} 1$ which in turn regulates SREBP activity. Activation of SREBP by SCAP yields an amino-terminal fragment which translocates to the nucleus to activate transcription of NPC1 and NPC2 genes (right).

NPC2 levels are stabilized by Nogo B receptor (left) while NPC1L1 protein promotes its degradation. NPC1 deficiency promotes NPC2 levels and vice versa. 


\section{NPC2}

Mutations in NPC2 yield "compensatory" increases in NPC1 protein [31]. NPC2 is stabilized by the Nogo- B receptor which has an independent role in lipogenesis by enhancing nuclear transport of liver X receptor alpha (LXR $\alpha$ ) while NPC1-Like 1 protein (NPC1L1) down-regulates the expression and secretion of NPC2 [58-60].

\section{Relationship to Cholesterol Sensing by mTORC1}

NPC1 forms a complex with the lysosomal transmembrane protein SLC38A9 which mediates cholesterol activation of mTOR complex 1 (mTORC1) [61]. mTORC1 regulates sterol regulatory element binding proteins (SREBP)1 and SREBP2 activity [62,63]. mTOR is a link between AD, in which mTOR is chronically activated with detrimental impact on autophagy and tau phosphorylation [6466], and schizophrenia which is characterized by hypofunction of the mTOR pathway [67].

\section{NPC Proteins as pharmacological targets}

NPC protein levels are sensitive to treatment with amphiphilic psychotropic and antidepressant drugs [68,69]. The cationic amphiphile U18666A binds to NPC1 [70], inhibits cholesterol binding and recapitulates features of NPC disease phenotype [71]. The antidepressant amitriptyline induces the accumulation of cytoplasmic cholesterol levels and increases expression of NPC2 mRNA [69].

Amitriptyline treatment increases the secretion of NPC2, causes neurogenesis and improves cognition in 3XTg Alzheimer's mice [72]. It also causes functional improvement in a Huntington's disease mouse model via increased neurotrophin signaling [73]. Amitriptyline has also shown benefit in the context of another neurodegenerative disease, progressive supranuclear palsy (PSP) [74, 75].

\section{Current treatment strategies}

Efforts to standardize disease diagnosis and treatment strategies have been reported [76]. Diagnosis of NPC disease typically involves histopathological analysis using filipin, a fluorescent macrolide antibiotic that binds to cholesterol. The compound has also been used extensively for chemical screening of compounds for the treatment of NPC [77-80]. A positive filipin test would prompt genetic testing for NPC1 or NPC2 mutations. Specific blood oxysterol profiles are associated with NPC disease [81]. The Phase 1-2 clinical trial for Intracerebroventricular (ICV) $\beta$-cyclodextrin employed plasma hydroxycholesterol [82], cerebrospinal fluid (CSF) fatty acid binding protein (FABP) and calbindin, a marker for Purkinje cell degeneration as biomarkers. In addition, various magnetic resonance modalities such as MRI have been employed as imaging biomarkers $[83,84]$.

Robust treatment approaches include ICV injections of $\beta$-cyclodextrin (BCD) which acts essentially as a cholesterol chaperone. $\mathrm{BCD}$ treatment is the result of novel research collaboration between academic, government and industry researchers and family members called Support of Accelerated Research-NPC (SOAR-NPC) [85].

Emerging therapies include: adenoviral-expressed wild-type NPC1 to provide functional NPC1 protein [86], stimulation of exosomal secretion of cholesterol to ameliorate abnormal accumulation of cholesterol [87], and knock-down of genes associated with ESCRT III (especially knock-down of VPS4B [88]) to increase exosome secretion [89].

NPC is associated not only with accumulation of cholesterol, but also with sphingosine, sphingomyelin and glycosphingolipids (GSL's) resulting in altered endolysosomal calcium homeostasis as a result of inhibiting the mucolipin TRP channel 1 (TRPML1) [9093]. The glycosylceramide synthase inhibitor Miglustat is approved for the treatment of NPC and reportedly stabilizes or improves neurological manifestations [76,94-96]. In the feline NPC model, the adverse neurological phenotype was delayed with miglustat treatment without having a significant impact on cholesterol accumulation or visceral endpoints suggesting that neurological manifestations and cholesterol accumulation, as well as central and peripheral manifestations are separable phenomena [97].

Treatment with fingolimod (FTY720), a sphingosine analog and sphingosine- 1-phosphate receptor agonist, increases NPC1 and NPC2 expression, and reduces both cholesterol and sphingolipids in NPC mutant cells [98]. Fingolimod, becomes a potent histone deacetylase (HDAC) inhibitor once phosphorylated. It is being evaluated in clinical trials for NPC disease and has been tested in the context of AD models [99]. Dysregulation of sphingolipid metabolism is observed in $\mathrm{AD}$ where it correlates with CSF A $\beta$ levels and contributes to impairment of autophagy [100-103].

Cellular treatment with sphingolipids causes a "molecular trap" for cholesterol Sphingolipid treatment results in SREBP cleavage by SREBP cleavage-activating protein (SCAP) [48], and subsequent upregulation of LDL receptors which is the source of the elevated cholesterol. LDL receptors as well as TMEM97/ 2 2, a protein that interacts with, and might regulate NPC1 levels are targets of SREBP [104]. In turn the lipogenic activity of SREBP1 is regulated by mTORC1 and promotes cell growth via Akt signaling [62].

\section{NPC and AD (Table 2)}

The observation of AD-like neurofibrillary tangles and diffuse amyloid deposits in NPC have prompted numerous studies to search for molecular links between these two diseases. For example, while there is little evidence for a direct genetic relationship between NPC and AD, there is reported epistasis between NPC1 and ATPbinding cassette type $\mathrm{A} 1$ (ABCA1) and $\mathrm{AD}$ risk [105]. ABCA1 is a critical lipidating gene for ApoE. ApoE4 is the strongest risk factor for sporadic $\mathrm{AD}$ and has been found to be poorly lipidated compared to the other common human ApoE isoforms, ApoE2 and ApoE3 [106]. Increasing ApoE4 lipidation has been suggested as a therapeutic strategy for $\mathrm{AD}$. It has been reported that NPC disease patients have dysregulated ABCA1 expression and reduced ABCA1 activity [107].

The NPC1 inhibitor U18666A, not only inhibits NPC1 cholesterol binding and recapitulate features of NPC disease phenotype [71], treatment with the drug alters APP metabolism resulting in endosomal - lysosomal processing of APP [108]. Knockout of the NPC1 gene has similar effects in vivo all suggesting that NPC proteins can influence the amyloidolytic processing of APP. Levels of NPC1 are increased in Alzheimer's disease and in APP/ PS1 transgenic animals [56,109], a surprising finding if the AD phenotype in NPC disease is thought to be the result of NPC1 or NPC2 loss of function. It is possible that such elevations in NPC protein levels reflect a homeostatic response 
to perturbed cholesterol metabolism in $\mathrm{AD}$.

Several additional studies have employed animal models of NPC disease (reviewed by [110]) crossed with models of AD. Deletion of either Tau or APP exacerbates the NPC phenotype $[111,112]$.

The deletion of tau is thought to impair the cytoplasmic transport required for autophagy, while the exacerbation of phenotype caused by the loss of APP suggests that APP may play a compensatory role for the loss of cholesterol transport proteins. $A \beta$ is reported to have a role in regulating lipid homeostasis and furthermore lipid-associated $\mathrm{A} \beta$ is increased in NPC suggesting a potential lipid "chaperone" role for the peptide. In contrast to APP deletion [113,114], APP overexpression in NPC-deficient background yields increased $A \beta$ generation and the production of shortened $\gamma$-C-terminal fragments ( $\gamma$-CTFs) suggesting correspondingly longer and potentially more toxic forms of $\mathrm{A} \beta$ [114-116].

APP, APP fragments and APP processing enzymes interact robustly with SREBP2, which in turn regulates NPC expression. A $\beta$ and $\beta$-cleaved APP inhibit SREBP2, while $\alpha$-soluble APP stimulates it $[117,118]$. The nuclear translocation of SREBP2 N-terminal fragments, which is required for SREBP transcriptional activation is impaired in AD and tau transgenic animals, but not in APP transgenic animals suggesting that AD-related tau dys-homeostasis can alter SREBP2 signaling [119]. Similarly, dysregulation of SREBP2 caused by high cholesterol conditions can cause an increase in the expression of beta-site amyloid precursor protein cleaving enzyme 1 (BACE1) under the same conditions expected to result in an increase in NPC expression [120].

\section{NPC and other neurodegenerative diseases}

NPC is a lysosomal storage disease, a category of neurodegenerative disorders that includes the sphingolipidoses. This class of disorders is characterized by aberrations in sphingolipid metabolism and includes Niemann-Pick disease types $A$ and $B$ caused by defects in sphingomyelinase (SMPD1), Gaucher's disease caused by galactosidase (GBA1) deficiency, Fabry's disease associated with $\alpha$ - galactosidase-A (GLA) deficiency, Krabbe disease associated with galactosidase (GALC) deficiency, Tay-Sachs caused by $\beta$-hexosaminidase-A mutations and metachromatic leukodystrophy (MLD) resulting from defects in arylsulfatase A (ARSA) [121]. Although cholesterol is the principle material impacted by NPC mutations, they also influence sphingolipid metabolism and therefore are included in this class of disorders all of which have devastating neurological consequences.

Due to the essential role NPC proteins play in cholesterol metabolism, it is not surprising that impairment of their function results in phenotypic overlap with numerous neurological diseases such as fronto-temporal dementia (FTD), Parkinson's disease, multiple sclerosis (MS) and other inflammatory disorders. The presence of frontal lobe atrophy suggests similarities with FTD [36]. A potential link with FTD is further supported by the observations that there is aberrant cytoplasmic localization of the FTD-related protein TAR DNA-binding protein 43 (TDP-43) in NPC models, and that the expression of TDP-43 regulated genes such as transcription factor AP-2 alpha (TFAP2A), ciliary neurotrophic factor receptor (CNTFR), MAP kinase-activating death domain protein (MADD), myocyte- specific enhancer factor 2D (MEF2D), transducin-like enhancer protein 1 (TLE1) and TRAF2 and NCK- interacting protein kinase (TNIK) is altered [122].

Parkinsonism is associated with NPC heterozygosity [25], and NPC cases share features of synucleinopathy associated with PD including Lewy bodies and Lewy neurites as detected by immunoreactivity for phosphorylated synuclein [20]. Ceramide metabolism appears to be perturbed in both NPC and PD $[90,91,98]$. Mutations in GBA1 cause Gaucher's disease when homozygous, or a predisposition to PD when heterozygous [123,124]. The accumulation of GSLs caused by GBA1 mutations can be mitigated with the pharmacological chaperone afegostat-tartrate (isofagomine) or with inhibitors of glycosylceramide synthase such as inhibitor GZ667161, which has been tested in models of synucleinopathy [125,126], and miglustat, which has been employed in NPC models and human NPC subjects as discussed above. Impaired mitophagy has been implicated in PD pathogenesis. NPC2 as well as the PD related genes parkin and PTEN-Induced kinase (PINK1) are regulators of mitochondrial autophagy suggesting a mechanistic link between NPC and PD $[40,127]$.

Cholesterol is a major component of myelin, so a relationship between diseases that result from dysregulation of cholesterol homeostasis and demyelinating diseases is expected. A case of adult NPC disease originally diagnosed as multiple sclerosis and a report of severe demyelination in a case of juvenile NPC disease illustrate the connection between aberrant cholesterol metabolism and impaired myelination of neurons. Defects in myelination are common both in human NPC disease and in the knockout mouse model and proteomic studies of the corpus callosum from knockout mice have identified specific factors involved in defective myelination including glycolipid transfer protein (GLTP), ceramide synthase 2 (CerS2), and 2-hydroxyacylsphingosine 1-beta-galactosyltransferase (UGT8). Fingolamod, a therapeutic approved for the treatment of MS is under evaluation for its utility in NPC disease. In the context of inflammation, NPC1 mutations are associated with activation of the innate immune system and chronic inflammation [128-132], however NPC2 knockdown reduced lipopolysaccharide (LPS)induced expression of pro-inflammatory genes suggesting Toll-like receptors (TLR) signaling activation requires NPC2 [40].

\section{NPC and other neurodevelopmental disorders}

In contrast to the features that are conventionally associated with $\mathrm{AD}, \mathrm{NPC}$ features psychosis as a component of disease phenotype, and stereotypy is a feature of both psychosis and NPC. Both NPC disease and schizophrenia are associated with cerebellar impairment [133-135]. Likewise seizure is a feature of NPC disease and AD. In a study on glutamatergic function in NPC1 -/- mice, AMPA receptors did not respond to prolonged application of agonist to cause a reduction in synaptic transmission despite normal AMPA receptor protein levels [136]. Similarly, studies on iPSC-derived NPC1 mutant neurons show upregulation of AMPA receptor expression and protein level, but attenuated function. Collectively, these data suggest that NPC protein plays an important role glutamatergic function.

As mentioned, TMEM97/ 22 is both a molecular partner of NPC1 and a robust target for antipsychotic medications suggesting a link 
Citation: Martone R, Gonzales C, Ramaswamy G. Niemann-Pick Type C Disease: At the Nexus of Neurodegenerative and Neurodevelopmental Disorders. J Parkinsons Dis Alzheimer Dis. 2019;6(1): 10.

between NPC and psychiatric disorders, while other psychotropic drugs upregulate expression of NPC1, NPC2 and other cholesterol transport genes through regulation of SREBP [68]. Large numbers of undiagnosed NPC mutations among psychiatric patients have been reported suggesting that psychosis may be a major manifestation of adult onset NPC disease $[27,137,138]$.

The neurodevelopmental - neurodegenerative disorder overlap: Alzheimer's disease + psychosis

If cholesterol metabolism is truly central to pathogenesis in both NPC and AD, it suggests that there may be additional phenotypic overlaps which are less commonly observed. Psychosis, for example, is a feature of NPC, and distinguishes an $\mathrm{AD}$ subtype. $\mathrm{AD}$ plus Psychosis $(\mathrm{AD}+\mathrm{P})$ is now recognized be associated with accelerated cognitive decline, hypofrontality and a significant (as much as $61 \%$ ) heritability $[7,8,139,140]$. Psychosis is reported in as many as $50 \%$ of individuals with $\mathrm{AD}$ and is associated with greater cortical synaptic impairment [9]. In the Tg4510 mouse model (P301L mutant human Tau), a psychosis phenotype (pre-pulse inhibition, PPI) correlates with brain load of hyperphosphorylated tau [141].

Treatment with the anti-psychotic haloperidol reduces tau phosphorylation in the same model by inhibiting AMPK consistent with postmortem human observation of reduced neurofibrillary load in subjects treated with haloperidol [142-144]. A psychotic phenotype was also described in the APPswe/PSI deltaE9 transgenic model, and rescued by knockdown of a protein linked to schizophrenia, kalirin [145].

ApoE genotype appears to correlate with both the occurrence of psychosis in $\mathrm{AD}$ and with the presence of Lewy body pathology, with those carrying two ApoE4 alleles at greatest risk [146,147].

\section{Discussion and Conclusion}

The NPC proteins regulate the critical transit of cholesterol through the endocytic pathway and as such appear to be prime targets for interventions into many pathogenic processes whether developmental or degenerative in origin [148]. The expression and stability of the NPC proteins are regulated by a diverse network of proteins, and NPC1 itself is the target of small molecule pharmacology efforts. Nevertheless, it is precisely that tie to diverse and potentially reciprocal processes that complicates targeting NPC- related processes and brings with it risks of off-target effects.

Given the central importance of cholesterol metabolism to $\mathrm{AD}$ and the fact that many NPC associated proteins are targets for antipsychotics, it should be no surprise that NPC disease is at the nexus of these diverse processes and highlights the heterogeneity of related diseases such as AD. Finding relationships between AD and neurodevelopmental processes is not unprecedented. Alterations of developmentally programmed gene expression and microchimerism have been evoked in claims that $\mathrm{AD}$ is neurodevelopmental in origin $[10,14]$. Moreover, there are clear links between AD and neurodevelopmental diseases based upon APP expression and metabolism, as in the case of Down's syndrome, in which increases in APP and A $\beta$ due to a gene dosage effect is observed. Conversely excess activity of $\alpha$-soluble APP is believed to contribute to brain enlargement in autism [149]. Furthermore, the tau pathology which is so central to the link between NPC and AD is also present in numerous other neurodevelopmental disorders, such as hemimegalencephaly, tuberous sclerosis complex and focal cortical dysplasia [150]. NPC disease exemplifies how cholesterol metabolism lies at the nexus of developmental and degenerative processes linking diverse phenotypes to common mechanisms.

\section{References}

1. Bonnot $\mathrm{O}$, Klünemann $\mathrm{HH}$, Velten $\mathrm{C}$, Torres Martin JV, Walterfang $\mathrm{M}$ et al (2019) Systematic review of psychiatric signs in Niemann-Pick disease type C. World J Biol Psychiatry 20: 320-332.

2. Vanier MT (2013) Niemann-Pick diseases. Handb Clin Neurol 113: 17171721.

3. Calabrese J, Khalili YA (2019) Psychosis in StatPearls. Treasure Island (FL).

4. Bondi MW, Edmonds EC, Salmon DP (2017) Alzheimer's disease: past, present, and future. J Int Neuropsychol Soc 23: 818-831.

5. Arenas F,Garcia-Ruiz C, Fernandez-Checa JC (2017) Intracellular Cholesterol Trafficking and Impact in Neurodegeneration. Front Mol Neurosci 10: 382.

6. Chen X, Hui L, Soliman ML, Geiger JD (2014) Altered Cholestero Intracellular Trafficking and the Development of Pathological Hallmarks of Sporadic AD. J Parkinsons Dis Alzheimers Dis 1.

7. Koppel J, Sunday S, Goldberg TE, Davies P, Christen E, et al. (2014) Psychosis in Alzheimer's disease is associated with frontal metabolic impairment and accelerated decline in working memory: findings from the Alzheimer's disease Neuroimaging Initiative. Am J Geriatr Psychiatr 22: 698707.

8. Sweet RA, Bennett DA, Graff-Radford NR, Mayeux R; National Institute on Aging Late-Onset Alzheimer's Disease Family Study Group (2010) Assessment and familial aggregation of psychosis in Alzheimer's disease from the National Institute on Aging Late Onset Alzheimer's Disease Family Study. Brain 133: 1155-1162.

9. Murray PS, Kumar S, Demichele-Sweet MA, Sweet RA (2014) Psychosis in Alzheimer's disease. Biol Psychiatry 75: 542-552.

10. Bothwell M, Giniger E (2000) Alzheimer's disease: neurodevelopment converges with neurodegeneration. Cell 102: 271-273.

11. Grilli M, Ferrari Toninelli G, Uberti D, Spano P, Memo M (2003) Alzheimer's disease linking neurodegeneration with neurodevelopment. Funct Neuro 18: $145-148$

12. Tapia-Rojas C, Inestrosa NC (2018) Loss of canonical Wnt signaling is involved in the pathogenesis of Alzheimer's disease. Neural Regen Res 13 1705-1710.

13. Tapia-Rojas C, Inestrosa NC (2018) Wnt signaling loss accelerates the appearance of neuropathological hallmarks of Alzheimer's disease in J20 APP transgenic and wild-type mice. J Neurochem 144: 443-465.

14. Arendt T, Stieler J, Ueberham U (2017) Is sporadic Alzheimer's disease a developmental disorder? J Neurochem 143: 396-408.

15. Vanier MT (2010) Niemann-Pick disease type C. Orphanet J Rare Dis 5: 16.

16. Gburek-Augustat J, Groeschel S, Kern J, Beck-Woedl S, Just J, et al.(2019) Comparative analysis of cerebral magnetic resonance imaging changes in nontreated infantile, juvenile and adult patients with Niemann-pick disease type C. Neuropediatrics

17. Patterson M (1993) Niemann-Pick Disease Type C. In: Adam MP, Ardinger $\mathrm{HH}$, Pagon RA, Wallace SE, Bean LJH, et al. (Eds). GeneReviews ${ }^{\circledR}$. Seattle (WA).

18. Greenberg CR, Barnes JG, Kogan S, Seargeant LE (2015) A rare case of Niemann-Pick disease type $C$ without neurological involvement in a 66-yearold patient. Mol Genet Metab Rep 3: 18-20.

19. Trendelenburg G, Vanier MT, Maza S, Millat G, Bohner G, et al. (2006) 
Citation: Martone R, Gonzales C, Ramaswamy G. Niemann-Pick Type C Disease: At the Nexus of Neurodegenerative and Neurodevelopmental Disorders. J Parkinsons Dis Alzheimer Dis. 2019;6(1): 10.

Niemann-Pick type C disease in a 68-year-old patient. J Neurol Neurosurg Psychiatry 77: 997-998.

20. Saito Y, Suzuki K, Hulette CM, Murayama S (2004) Aberrant phosphorylation of alpha-synuclein in human Niemann-Pick type C1 disease. J Neuropathol Exp Neurol 63: 323-328

21. Malnar M, Hecimovic S, Mattsson N, Zetterberg H (2014) Bidirectional links between Alzheimer's disease and Niemann-Pick type $\mathrm{C}$ disease. Neurobiol Dis $72: 37-47$

22. Sarna JR, Hawkes R (2003) Patterned Purkinje cell death in the cerebellum Prog Neurobiol 70: 473-507.

23. Sarna JR, Larouche M, Marzban H, Sillitoe RV, Rancourt DE, et al. (2013) Patterned Purkinje cell degeneration in mouse models of Niemann-Pick type C disease. J Comp Neurol 456: 279-291.

24. Lamri A, Pigeyre M, Garver WS, Meyre D (2018) The extending spectrum of NPC1-related human disorders: from Niemann-Pick C1 disease to obesity. Endocr Rev 39: 192-220.

25. Kluenemann HH, Nutt JG, Davis MY, Bird TD (2013) Parkinsonism syndrome in heterozygotes for Niemann-Pick C. J Neurol Sci 335: 219-220.

26. Wassif CA, Cross JL, Iben J, Sanchez-Pulido L, Cougnoux A, et al. (2016) High incidence of unrecognized visceral/neurological late-onset NiemannPick disease, type $\mathrm{C} 1$, predicted by analysis of massively parallel sequencing data sets. Genet Med 18: 41-48.

27. Bauer $P$, Balding DJ, Klünemann HH, Linden DE, Ory DS, et al. (2013) Genetic screening for Niemann-Pick disease type $C$ in adults with neurological and psychiatric symptoms: findings from the ZOOM study. Hum Mol Genet 22: 4349-4356.

28. Subramanian K, Balch WE (2008) NPC1/NPC2 function as a tag team duo to mobilize cholesterol. Proc Natl Acad Sci U S A 105: 15223-15224.

29. Jelinek D, Patrick SM, Kitt KN, Chan T, Francis GA, et al. (2009) Physiological and coordinate downregulation of the NPC1 and NPC2 genes are associated with the sequestration of LDL-derived cholesterol within endocytic compartments. J Cell Biochem 108: 1102-1116.

30. Gong X, Qian H, Zhou X, Wu J, Wan T, et al. (2016) Structural insights into the Niemann-Pick C1 (NPC1)-mediated cholesterol transfer and ebola infection. Cell 165: 1467-1478.

31. Millat G, Marçais C, Tomasetto C, Chikh K, Fensom AH, et al. (2001) Niemann-Pick C1 disease: correlations between NPC1 mutations, levels of NPC1 protein, and phenotypes emphasize the functional significance of the putative sterol-sensing domain and of the cysteine-rich luminal loop. Am J Hum Genet 68: 1373-1385.

32. Shammas H, Kuech EM, Rizk S, Das AM, Naim HY, et al. (2019) Different Niemann-Pick C1 genotypes generate protein phenotypes that vary in their intracellular processing, trafficking and localization. Sci Rep 9: 5292.

33. Formichi P, Battisti C, De Santi MM, Guazzo R, Tripodi SA et al. (2018) Primary cilium alterations and expression changes of Patched1 proteins in niemann-pick type C disease. J Cell Physiol 233: 663-672.

34. Davies JP, Chen FW, loannou YA (2000) Ioannou, Transmembrane molecular pump activity of Niemann- Pick C1 protein. Science 290: 22952298

35. Millat G, Chikh K, Naureckiene S, Sleat DE, Fensom AH, et al. (2001) Niemann-Pick disease type C: spectrum of HE1 mutations and genotype/ phenotype correlations in the NPC2 group. Am J Hum Genet 69: 1013-1021.

36. Klunemann HH, Elleder M, Kaminski WE, Snow K, Peyser JM, et al. (2002) Frontal lobe atrophy due to a mutation in the cholesterol binding protein HE1/NPC2. Ann Neurol 52: 743-749.

37. Liou HL, Dixit SS, Xu S, Tint GS, Stock AM, et al. (2006) NPC2, the protein deficient in Niemann-Pick C2 disease, consists of multiple glycoforms that bind a variety of sterols. J Biol Chem 281: 36710-36723.

38. Infante RE, Wang ML, Radhakrishnan A, Kwon HJ, Brown MS, et al. (2008) NPC2 facilitates bidirectional transfer of cholesterol between NPC1 and lipid bilayers, a step in cholesterol egress from lysosomes. Proc Natl Acad Sci U

\section{S A 105: 15287-15292.}

39. Kennedy BE, Charman M, Karten B (2012) Niemann-Pick Type C2 protein contributes to the transport of endosomal cholesterol to mitochondria without interacting with NPC1. J Lipid Res 53: 2632-2642.

40. Guo H, Zhao M, Qu X, Deis JA, Huang H, et al. (2016) Niemann-Pick type C2 deficiency impairs autophagy-lysosomal activity, mitochondrial function, and TLR signaling in adipocytes. J Lipid Res 57: 1644-1658.

41. Wei J, Zhang YY, Luo J, Wang JQ, Zhou YX, et al. (2017) The GARP Complex Is Involved in Intracellular Cholesterol Transport via Targeting NPC2 to Lysosomes. Cell Rep 19: 2823-2835.

42. Hannaford J, Guo H, Chen X (2013) Involvement of cathepsins B and L in inflammation and cholesterol trafficking protein NPC2 secretion in macrophages. Obesity (Silver Spring) 21: 1586-1595.

43. Araki N, Ishigami T, Ushio H, Minegishi S, Umemura M, et al. (2009) Identification of NPC2 protein as interaction molecule with C2 domain of human Nedd4L. Biochem Biophys Res Commun 388: 290-296.

44. Broix L, Jagline H, Ivanova E, Schmucker S, Drouot N, et al. (2016) Mutations in the HECT domain of NEDD4L lead to AKT-mTOR pathway deregulation and cause periventricular nodular heterotopia. Nat Genet 48: 1349- 1358.

45. Ebrahimi-Fakhari D, Wahlster L, Hoffmann GF, Kölker S (2014) Emerging role of autophagy in pediatric neurodegenerative and neurometabolic diseases. Pediatr Res 75: 217-226.

46. Ebrahimi-Fakhari D, Wahlster L, Bartz F, Werenbeck-Ueding J, Praggastis M, et al. (2016) Reduction of TMEM97 increases NPC1 protein levels and restores cholesterol trafficking in Niemann-pick type $\mathrm{C} 1$ disease cells. Hum Mol Genet 25: 3588-3599.

47. Riad A, Zeng C, Weng CC, Winters H, Xu K, et al. (2018) Sigma-2 Receptor/ TMEM97 and PGRMC-1 Increase the Rate of Internalization of LDL by LDL Receptor through the Formation of a Ternary Complex. Sci Rep 8: 16845.

48. Zhang Y, Ma KL, Ruan XZ, Liu BC (2016) Dysregulation of the Low-Density lipoprotein receptor pathway is involved in lipid disorder-mediated organ injury. Int J Biol Sci 12: 569-579.

49. Pietiainen V, Vassilev B, Blom T, Wang W, Nelson J, et al. (2013) NDRG1 functions in LDL receptor trafficking by regulating endosomal recycling and degradation. J Cell Sci 126: 3961-3971.

50. Qin Q, Liao G, Baudry M, Bi X (2010) Cholesterol perturbation in mice results in p53 degradation and Axonal Pathology through p38 MAPK and Mdm2 Activation. PLoS One 5: 9999.

51. Jembrek MJ, Slade N, Hof PR, Šimić G (2018) The interactions of p53 with tau and $A \beta$ as potential therapeutic targets for Alzheimer's disease. Prog Neurobiol 168: 104-127.

52. Buizza L, Prandelli C, Bonini SA, Delbarba A, Cenini G, et al. (2013) Conformational altered p53 affects neuronal function: relevance for the response to toxic insult and growth-associated protein 43 expression. Cell Death Dis 4: 484

53. Lanni C, Racchi M, Mazzini G, Ranzenigo A, Polotti R, et al. (2008) Conformationally altered p53: a novel Alzheimer's disease marker? Mol Psychiatry 13: 641-647.

54. Vazquez MC, del Pozo T, Robledo FA, Carrasco G, Pavez L, et al. ( 2011) Alteration of gene expression profile in Niemann-Pick type $\mathrm{C}$ mice correlates with tissue damage and oxidative stress. PLoS One 6: 28777.

55. Davis W Jr (2015) The ATP-Binding Cassette Transporter-2 (ABCA2) Overexpression Modulates Sphingosine Levels and Transcription of the Amyloid Precursor Protein (APP) Gene. Curr Alzheimer Res 12: 847-859.

56. Kodam A, Maulik M, Peake K, Amritraj A, Vetrivel KS, et al. (2010) Altered levels and distribution of amyloid precursor protein and its processing enzymes in Niemann-Pick type C1-deficient mouse brains. Glia 58: 12671281.

57. Du X, Zhang Y, Jo SR, Liu X, Qi Y, et al. (2015) Akt activation increases cellular cholesterol by promoting the proteasomal degradation of NiemannPick C1. Biochem J 471: 243-253. 
Citation: Martone R, Gonzales C, Ramaswamy G. Niemann-Pick Type C Disease: At the Nexus of Neurodegenerative and Neurodevelopmental Disorders. J Parkinsons Dis Alzheimer Dis. 2019;6(1): 10.

58. Harrison $K D$, Miao $R Q$, Fernandez-Hernándo $C$, Suárez $Y$, Dávalos $A$, et al. (2009) Nogo-B receptor stabilizes Niemann-Pick type C2 protein and regulates intracellular cholesterol trafficking. Cell Metab 10: 208-218.

59. Hu W, Zhang W, Chen Y, Rana U, Teng RJ, et al. (2016) Nogo-B receptor deficiency increases liver $X$ receptor alpha nuclear translocation and hepatic lipogenesis through an adenosine monophosphate-activated protein kinase alpha- dependent pathway. Hepatology 64: 1559-1576.

60. Yamanashi Y, Takada T, Shoda J, Suzuki H (2012) Novel function of Niemann-Pick C1-like 1 as a negative regulator of Niemann-Pick C2 protein. Hepatology 55: 953-964.

61. Castellano BM, Thelen AM, Moldavski O, Feltes M, van der Welle RE, et al. (2017) Lysosomal cholesterol activates mTORC1 via an SLC38A9Niemann-Pick C1 signaling complex. Science 355: 1306-1311.

62. Porstmann T, Santos CR, Griffiths B, Cully M, Wu M, et al. (2008) SREBP activity is regulated by $\mathrm{mTORC} 1$ and contributes to Akt-dependent cell growth. Cell Metab. 8: 224-236.

63. Eid W, Dauner K, Courtney KC, Gagnon A, Parks RJ, et al. (2017) mTORC1 activates SREBP-2 by suppressing cholesterol trafficking to lysosomes in mammalian cells. Proc Natl Acad Sci U S A 114: 7999-8004.

64. Oddo S (2012) The role of mTOR signaling in Alzheimer disease. Front Biosci (Schol Ed) 4: 941-952.

65. Caccamo A, Magrì A, Medina DX, Wisely EV, López-Aranda MF, et al. (2013) mTOR regulates tau phosphorylation and degradation: implications for Alzheimer's disease and other tauopathies. Aging Cell 12: 370-80.

66. Mueed Z, Tandon P, Maurya SK, Deval R, Kamal MA, et al. (2018) Tau and mTOR: The Hotspots for Multifarious Diseases in Alzheimer's Development. Front Neurosci 12: 1017

67. Gururajan A, van den Buuse M (2014) Is the mTOR-signalling cascade disrupted in Schizophrenia? J Neurochem 129: 377-387.

68. Vik-Mo AO, Fernø J, Skrede S, Steen VM (2009) Psychotropic drugs upregulate the expression of cholesterol transport proteins including ApoE in cultured human CNS- and liver cells. BMC Pharmacol 9: 10.

69. Zschocke J, Zimmermann N, Berning B, Ganal V, Holsboer F, et al (2011) Antidepressant drugs diversely affect autophagy pathways in astrocytes and neurons--dissociation from cholesterol homeostasis. Neuropsychopharmacology 36: 1754-1768.

70. Lu F, Liang Q, Abi-Mosleh L, Das A, De Brabander JK, et al. (2015) Identification of NPC1 as the target of U18666A, an inhibitor of lysosomal cholesterol export and Ebola infection. Elife 4: pii: e12177.

71. Shoemaker CJ, Schornberg KL, Delos SE, Scully C, Pajouhesh H, et al (2013) Multiple cationic amphiphiles induce a Niemann-Pick C phenotype and inhibit Ebola virus entry and infection. PLoS One 8: 56265.

72. Chadwick W, Mitchell N, Caroll J, Zhou Y, Sung-Soo P, et al. (2011) Amitriptyline-mediated cognitive enhancement in aged 3xTg Alzheimer's disease mice is associated with neurogenesis and neurotrophic activity. PLoS One 6: 21660.

73. Cong WN, Chadwick W, Wang R, Daimon CM, Cai H, et al. (290) Amitriptyline improves motor function via enhanced neurotrophin signaling and mitochondrial functions in the murine $\mathrm{N} 171-82 \mathrm{Q}$ Huntington disease model. J Biol Chem 2015. 290: 2728-2743.

74. Nieforth KA, Golbe L (1993) Retrospective study of drug response in 87 patients with progressive supranuclear palsy. Clin Neuropharmacol 16: 338 346.

75. Engel PA (1996) Treatment of progressive supranuclear palsy with amitriptyline: therapeutic and toxic effects. J Am Geriatr Soc 44: 1072-1074.

76. NP-C Guidelines Working Group, Wraith JE, Baumgartner MR, Bembi B, Covanis A, et al. (2009) Recommendations on the diagnosis and management of Niemann-Pick disease type C. Mol Genet Metab 98: 152-65

77. Pugach EK, Feltes M, Kaufman RJ, Ory DS, Bang AG, et al. (2018) Highcontent screen for modifiers of Niemann-Pick type $C$ disease in patient cells. Hum Mol Genet 27: 2101-2112.
78. Pipalia NH, Cosner CC, Huang A, Chatterjee A, Bourbon P, et al. (2011) Histone deacetylase inhibitor treatment dramatically reduces cholesterol accumulation in Niemann-Pick type C1 mutant human fibroblasts. Proc Natl Acad Sci U S A 108: 5620-5625.

79. Rujoi M, Pipalia NH, Maxfield FR (2010) Cholesterol pathways affected by small molecules that decrease sterol levels in Niemann-Pick type C mutant cells. PLoS One 5: 12788.

80. Rosenbaum Al, Rujoi M, Huang AY, Du H, Grabowski GA, et al. (2009) Chemical screen to reduce sterol accumulation in Niemann-Pick $C$ disease cells identifies novel lysosomal acid lipase inhibitors. Biochim Biophys Acta 1791: 1155-1165.

81. Porter FD, Scherrer DE, Lanier MH, Langmade SJ, Molugu V, et al. (2010) Cholesterol oxidation products are sensitive and specific blood-based biomarkers for Niemann-Pick C1 disease. Sci Transl Med 2: 56ra81.

82. Ory DS, Ottinger EA, Farhat NY, King KA, Jiang X, et al. (2017) Intrathecal 2-hydroxypropyl- $\beta$-cyclodextrin decreases neurological disease progression in Niemann-Pick disease, type C1: a non-randomised, open-label, phase 1-2 trial. Lancet 390: 1758-1768.

83. Bradbury A, Bagel J, Sampson M, Farhat N, Ding W, et al. (2016) Cerebrospinal Fluid Calbindin D Concentration as a Biomarker of Cerebellar Disease Progression in Niemann-Pick Type C1 Disease. J Pharmacol Exp Ther 358: 254-261.

84. Benussi A, Cotelli MS, Padovani A, Borroni B, et al. (2018) Recent neuroimaging, neurophysiological, and neuropathological advances for the understanding of NPC. F1000Res 7: 194.

85. Walkley SU, Davidson CD, Jacoby J, Marella PD, Ottinger EA, et al. (2016) Fostering collaborative research for rare genetic disease: the example of Niemann-Pick type C disease. Orphanet J Rare Dis 11: 161.

86. Xie C, Gong XM, Luo J, Li BL, Song BL (2017) AAV9-NPC1 significantly ameliorates Purkinje cell death and behavioral abnormalities in mouse NPC disease. J Lipid Res 58: 512-518.

87. Strauss K, Goebel C, Runz H, Möbius W, Weiss S, et al. (2010) Exosome secretion ameliorates lysosomal storage of cholesterol in Niemann- Pick type C disease. J Biol Chem 285: 26279-26288.

88. Colombo M, Moita C, van Niel G, Kowal J, Vigneron J, et al. (2013) Analysis of ESCRT functions in exosome biogenesis, composition and secretion highlights the heterogeneity of extracellular vesicles. J Cell Sci 126: 555355565.

89. Hessvik NP, Llorente A (2018) Current knowledge on exosome biogenesis and release. Cell Mol Life Sci 75: 193-208.

90. Lloyd-Evans E, Morgan AJ, He X, Smith DA, Elliot-Smith E, et al. (2008) Niemann-Pick disease type $C 1$ is a sphingosine storage disease that causes deregulation of lysosomal calcium. Nat Med 14: 1247-55.

91. Newton J, Milstien S, Spiegel S (2018) Niemann-Pick type C disease: The atypical sphingolipidosis. Adv Biol Regul 70: 82-88.

92. Lloyd-Evans E, Waller-Evans H, Peterneva K, Platt FM, et al. (2010) Endolysosomal calcium regulation and disease. Biochem Soc Trans. 38 1458-1464.

93. Shen D, Wang X, Li X, Zhang X, Yao Z, et al. (2012) Lipid storage disorders block lysosomal trafficking by inhibiting a TRP channel and lysosomal calcium release. Nat Commun 3: 731

94. Pineda M, Walterfang M, Patterson MC (2018) Miglustat in Niemann-Pick disease type C patients: a review. Orphanet J Rare Dis 13: 140.

95. Lyseng-Williamson KA (2014) Miglustat: a review of its use in Niemann-Pick disease type C. Drugs 74: 61-74.

96. Patterson MC, Clayton P, Gissen P, Anheim M, Bauer P (2017) Recommendations for the detection and diagnosis of Niemann-Pick disease type C: An update. Neurol Clin Pract 7: 499-511.

97. Stein VM, Crooks A, Ding W, Prociuk M, O'Donnell P, et al. (2012) Miglustat improves purkinje cell survival and alters microglial phenotype in feline Niemann-Pick disease type C. J Neuropathol Exp Neurol 71: 434-448. 
Citation: Martone R, Gonzales C, Ramaswamy G. Niemann-Pick Type C Disease: At the Nexus of Neurodegenerative and Neurodevelopmental Disorders. J Parkinsons Dis Alzheimer Dis. 2019;6(1): 10.

98. Newton J, Hait NC, Maceyka M, Colaco A, Maczis M, et al. (2017) FTY720 fingolimod increases NPC1 and NPC2 expression and reduces cholestero and sphingolipid accumulation in Niemann-Pick type $\mathrm{C}$ mutant fibroblasts. FASEB J 31: 1719-1730.

99. Brunkhorst R, Vutukuri R, Pfeilschifter W (2014) Fingolimod for the treatment of neurological diseases-state of play and future perspectives. Front Cell Neurosci 8: 283.

100. He X, Huang Y, Li B, Gong CX, Schuchman EH, et al. (2010) Deregulation of sphingolipid metabolism in Alzheimer's disease. Neurobiol Aging 31: 398408.

101. Clausznitzer D, Pichardo-Almarza C, Relo AL, van Bergeijk J, van der Kam E, et al. (2018) Quantitative Systems pharmacology model for Alzheimer disease indicates targeting sphingolipid dysregulation as potential treatment option. CPT Pharmacometrics Syst Pharmacol 7: 759-770.

102. Fonteh AN, Ormseth C, Chiang J, Cipolla M, Arakaki X, et al. (2015) Sphingolipid metabolism correlates with cerebrospinal fluid Beta amyloid levels in Alzheimer's disease. PLoS One 10: 0125597

103. Lee JK, Jin HK, Park MH, Kim BR, Lee PH, et al. (2014) Acid sphingomyelinase modulates the autophagic process by controlling lysosomal biogenesis in Alzheimer's disease. J Exp Med 211: 1551-1570.

104. Osborne TF, Espenshade PJ (2009) Evolutionary conservation and adaptation in the mechanism that regulates SREBP action: what a long, strange tRIP it's been. Genes Dev 23: 2578-2591.

105. Rodriguez-Rodriguez E, Vázquez-Higuera JL, Sánchez-Juan P, Mateo I, Pozueta A, et al. (2010) Epistasis between intracellular cholestero trafficking-related genes (NPC1 and ABCA1) and Alzheimer's disease risk. J Alzheimers Dis 21: 619-625.

106. Suidan GL, Ramaswamy G (2019) Targeting Apolipoprotein E for Alzheimer's disease: An industry perspective. Int J Mol Sci 20.

107. Choi HY, Karten B, Chan T, Vance JE, Greer WL, et al. (2003) Impaired ABCA1-dependent lipid efflux and hypoalphalipoproteinemia in human Niemann-Pick type C disease. J Biol Chem 278: 32569-32577.

108. Chung J, Phukan G, Vergote D, Mohamed A, Maulik M, et al. (2019) Endosomal-Lysosomal cholesterol sequestration by U18666A differentially regulates Amyloid Precursor Protein (APP) Metabolism in Normal and APP Overexpressing Cells. Mol Cell Biol 38

109. Kagedal K, Kim WS, Appelqvist H, Chan S, Cheng D, et al. (2010) Increased expression of the lysosomal cholesterol transporter NPC1 in Alzheimer's disease. Biochim Biophys Acta 1801: 831-838.

110. Fog CK, Kirkegaard T (2019) Animal models for Niemann-Pick type C implications for drug discovery \& development. Expert Opin Drug Discov 14: 499-509.

111. Pacheco CD, Elrick MJ, Lieberman AP (2009) Tau deletion exacerbates the phenotype of Niemann-Pick type $\mathrm{C}$ mice and implicates autophagy in pathogenesis. Hum Mol Genet 18: 956-965

112. Nunes A, Pressey SN, Cooper JD, Soriano S (2011) Loss of amyloid precursor protein in a mouse model of Niemann-Pick type $C$ disease exacerbates its phenotype and disrupts tau homeostasis. Neurobiol Dis 42: 349-359.

113. Grosgen S, Grimm MOW, Friess P, Hartmann T (2010) Role of amyloid beta in lipid homeostasis. Biochim Biophys Acta 1801: 966-974.

114. Boland B, Smith DA, Mooney D, Jung SS, Walsh DM, et al. (2010) Macroautophagy is not directly involved in the metabolism of amyloid precursor protein. J Biol Chem 285: 37415-37426.

115. Maulik M, Peake K, Chung J, Wang Y, Vance JE, et al. (2015) APP overexpression in the absence of NPC1 exacerbates metabolism of amyloidogenic proteins of Alzheimer's disease. Hum Mol Genet 24: 71327150.

116. Borbon IA, Erickson RP (2011) Interactions of Npc1 and amyloid accumulation/deposition in the APP/PS1 mouse model of Alzheimer's. J Appl Genet 52: 213-218
117. Mohamed A, Viveiros A, Williams K, Posse de Chaves E (2018) Abeta inhibits SREBP-2 activation through Akt inhibition. J Lipid Res 59: 1-13.

118. Wang W, Mutka AL, Zmrzljak UP, Rozman D, Tanila H, et al. (2014) Amyloid precursor protein alpha- and beta-cleaved ectodomains exert opposing control of cholesterol homeostasis via SREBP2. FASEB J 28: 849-860.

119. Wang C, Zhao F, Shen K, Wang W, Siedlak SL, Lee HG, et al. (2019) The sterol regulatory element-binding protein 2 is dysregulated by tau alterations in Alzheimer disease. Brain Pathol 29: 530-543.

120. Mastrocola R, Guglielmotto M, Medana C, Catalano MG, Cutrupi S, et al (2011) Dysregulation of SREBP2 induces BACE1 expression. Neurobiol Dis 44: 116-124.

121. Eckhardt M (2010) Pathology and current treatment of neurodegenerative sphingolipidoses. Neuromolecular Med 12: 362-382.

122. Dardis A, Zampieri S, Canterini S, Newell KL, Stuani C, et al. (2016) Altered localization and functionality of TAR DNA Binding Protein 43 (TDP-43) in Niemann-Pick disease type C. Acta Neuropathol Commun 4: 52.

123. Bras J, Singleton A, Cookson MR, Hardy J (2008) Emerging pathways in genetic Parkinson's disease: Potential role of ceramide metabolism in Lewy body disease. FEBS J 275: 5767-5773.

124. Lwin A, Orvisky E, Goker-Alpan O, LaMarca ME, Sidransky E, et al. (2004) Glucocerebrosidase mutations in subjects with parkinsonism. Mol Genet Metab 81: 70-73.

125. Richter F, Fleming SM, Watson M, Lemesre V, Pellegrino L, et al. (2014) A GCase chaperone improves motor function in a mouse model of synucleinopathy. Neurotherapeutics 11: 840-856.

126. Sardi SP, Viel C, Clarke J, Treleaven CM, Richards AM, et al. (2017) Glucosylceramide synthase inhibition alleviates aberrations in synucleinopathy models. Proc Natl Acad Sci U S A 114: 2699-2704.

127. Liu J, Liu W, Li R, Yang H (2019) Mitophagy in Parkinson's Disease: From Pathogenesis to Treatment. Cells 8.

128. Grau AJ, Brandt T, Weisbrod M, Niethammer R, Forsting M, et al. (1997) Adult Niemann-Pick disease type $\mathrm{C}$ mimicking features of multiple sclerosis. J Neurol Neurosurg Psychiatry 63: 552.

129. Kodachi T, Matsumoto S, Mizuguchi M, Osaka H, Kanai N, et al. (2017) Severe demyelination in a patient with a late infantile form of Niemann-Pick disease type C. Neuropathology 37: 426-430.

130. Yu T, Lieberman AP (2013) Npc1 acting in neurons and glia is essential for the formation and maintenance of CNS myelin. PLoS Genet. 9: 1003462.

131. Yang F, Guan Y, Feng X, Rolfs A, Schlüteret H, et al. (2019) Proteomics of the corpus callosum to identify novel factors involved in hypomyelinated Niemann-Pick Type C disease mice. Mol Brain 12: 17.

132. Platt N, Speak AO, Colaco A, Gray J, Smith DA, et al. (2016) Immune dysfunction in Niemann-Pick disease type C. J Neurochem 136: 74-80.

133. Jurjus GJ, Weiss KM, Jaskiw GE (1994) Schizophrenia-like psychosis and cerebellar degeneration. Schizophr Res 12: 183-184.

134.Liang KJ, Carlson ES (2019) Resistance, vulnerability and resilience: A review of the cognitive cerebellum in aging and neurodegenerative diseases. Neurobiol Learn Mem pii: S1074-7427(19)30005-X.

135. Cao H, Chen OY, Chung Y, Forsyth JK, McEwen SC, et al. (2018) Cerebellothalamo-cortical hyperconnectivity as a state-independent functional neural signature for psychosis prediction and characterization. Nat Commun 9 : 3836 .

136. D'Arcangelo G, Grossi D, De Chiara G, de Stefano MC, Cortese G, et al (2011) Glutamatergic neurotransmission in a mouse model of Niemann-Pick type C disease. Brain Res 1396: 11-19.

137. Maubert A, Hanon C, Metton JP (2013) Adult onset Niemann-Pick type C disease and psychosis: literature review. Encephale 39: 315-319.

138. Maubert A, Hanon C, Sedel F (2016) Psychiatric disorders in adult form of Niemann-Pick disease type C. Encephale 42: 208-213. 
Citation: Martone R, Gonzales C, Ramaswamy G. Niemann-Pick Type C Disease: At the Nexus of Neurodegenerative and Neurodevelopmental Disorders. J Parkinsons Dis Alzheimer Dis. 2019;6(1): 10.

139. Koppel J, Greenwald BS (2014) Optimal treatment of Alzheimer's disease psychosis: challenges and solutions. Neuropsychiatr Dis Treat 10: 22532262.

140.Koppel J, Goldberg TE, Gordon ML, Huey E, Davies P, et al. (2012) Relationships between behavioral syndromes and cognitive domains in Alzheimer disease: the impact of mood and psychosis. Am J Geriat Psychiatry 20: 994-1000.

141. Koppel J, Jimenez H, Azose M, D’Abramo C, Acker C, et al. (2014) Pathogenic tau species drive a psychosis-like phenotype in a mouse mode of Alzheimer's disease. Behav Brain Res 275: 27-33.

142. Koppel J, Jimenez H, Adrien L, Greenwald BS, Marambaud P, et al. (2016) Haloperidol inactivates AMPK and reduces tau phosphorylation in a tau mouse model of Alzheimer's disease. Alzheimers Dement (N Y) 2: 121-130.

143. Arnold SE, Franz BR, Trojanowski JQ (1994) Elderly patients with schizophrenia exhibit infrequent neurodegenerative lesions. Neurobio Aging 15: 299-303.

144. Purohit DP, Davidson M, Perl DP, Powchik P, Haroutunian VH, et al. (1993) Severe cognitive impairment in elderly schizophrenic patients: a clinicopathological study. Biol Psychiatry 33: 255-260.

145. Krivinko JM, Krivinko JM, Erickson SL, Abrahamson EE, Wills ZP, et al (2017) Kalirin reduction rescues psychosis-associated behavioral deficits in APPswe/PSEN1dE9 transgenic mice. Neurobiol Aging 54: 59-70.
146. Kim J, Fischer CE, Schweizer TA, Munoz DG (2017) Gender and pathologyspecific effect of apolipoprotein e genotype on psychosis in Alzheimer's disease. Curr Alzheimer Res 14: 834-840.

147. Qian W, Fischer CE, Schweizer TA, Munoz DG (2018) Association between psychosis phenotype and APOE genotype on the clinical profiles of Alzheimer's Disease. Curr Alzheimer Res 15: 187-194.

148. Ory DS (2009) Getting a "Hold" on NPC2. Cell Metab 10: 161-162.

149. Sokol DK, Maloney B, Westmark CJ, Lahiri DK (2019) Novel Contribution of Secreted Amyloid-beta Precursor Protein to White Matter Brain Enlargement in Autism Spectrum Disorder. Front Psychiatry 10: 165.

150. Rankovic M, Zweckstetter M (2019) Upregulated levels and pathological aggregation of abnormally phosphorylated Tau-protein in children with neurodevelopmental disorders. Neurosci Biobehav Rev 98: 1-9.

151. Yao J, Ho D, Calingasan NY, Pipalia NH, Lin MT, et al. (2012) Neuroprotection by cyclodextrin in cell and mouse models of Alzheimer disease. J Exp Med 209: 2501-2513.

152. Yang DS, Stavrides P, Kumar A, Jiang Y, Mohan PS, et al. (2017) Cyclodextrin has conflicting actions on autophagy flux in vivo in brains of normal and Alzheimer model mice. Hum Mol Genet 26: 843-859.

153. Maulik M, Ghoshal B, Kim J, Wang Y, Yang J, et al. (2012) Mutant human APP exacerbates pathology in a mouse model of NPC and its reversal by a beta-cyclodextrin. Hum Mol Genet 21: 4857-75.

154.Fu R, Yanjanin NM, Elrick MJ, Ware C, Lieberman AP, et al. (2012) Apolipoprotein $E$ genotype and neurological disease onset in Niemann-Pick disease, type C1. Am J Med Genet A 158: 2775-2780.

\section{Acknowledgement}

We thank Dominic M. Walsh for his insightful review of the manuscript. 